\title{
Identifying United States and Territory Education Requirements for Childhood Vaccination Exemptions
}

Lacey M Eden ${ }^{1 *}$, Emily G. Dunn ${ }^{1}$, Karlen E.Luthy ${ }^{1}$, Katelyn Wells ${ }^{2}$, Janelle Macintosh ${ }^{1}$ and Renea Beckstrand $^{1}$

1474 SWKT College of Nursing, Brigham Young University Provo, UT 84602, USA

${ }^{2}$ Association of Immunization Managers, 620 Hungerford Dr. Suite 29, Rockville, MD 20850, USA

"Corresponding author: Lacey M Eden, Assistant Teaching Professor, 474 SWKT College of Nursing, Brigham Young University Provo, UT 84602, USA, Tel: 801-471-8789, 801-422-6891; E-mail: Lacey_eden@byu.edu

Received date: May 25, 2017; Accepted date: June 13, 2017; Published date: June 20, 2017

Copyright: $@ 2017$ Eden LM, et al. This is an open-access article distributed under the terms of the Creative Commons Attribution License, which permits unrestricted use, distribution, and reproduction in any medium, provided the original author and source are credited.

\begin{abstract}
Background: Children are required by law to receive vaccinations to enter school. States and territories offer exemptions for parents who refuse to vaccinate their children. Types of exemptions vary by state or territory, as does the exemption filing process. The purpose of this research was to identify the various education-related processes implemented by states and territories which allow parents to exempt children from vaccinations.

Methods: A questionnaire was distributed to immunization program managers in the 50 United States, District of Columbia, the United States Indian Health Service, and eight United States territories. Managers reported vaccination requirements for their jurisdiction (collectively referred to as "state"). Education-related questions identified which states required parents to: 1) read and sign a vaccination risk/benefit statement prior to exemption; 2) complete mandatory vaccine education before obtaining vaccination exemption; 3) complete education within a certain time period before school admission. Additionally, states were asked how parental vaccine education was regulated.
\end{abstract}

Results: A parent-signed risk/benefit statement was required by 25 states for religious exemptions, 12 states for personal exemptions, 10 states for medical exemptions, and 1 state for temporary medical exemptions. Thirteen states required mandatory parental vaccine education prior to obtaining an exemption. For states that mandated parental vaccine education prior to exemption, the education was most commonly regulated by statute, verses administrative rule or school policy.

Conclusions: Vaccine education requirements and the process for providing this education to parents seeking immunization exemptions vary greatly between the states. More research is needed to fully understand the impact of the education requirement on exemption rates. Familiarity with and effectiveness of various state vaccine education requirements may aid policymakers who are considering enacting mandatory vaccine education in their state.

Keywords: Vaccine; Immunizations; Exemption; Requirements; Legislation; Policy; Education

\section{Introduction}

Immunizations are one of the greatest public health accomplishments of all time [1]. In the early 1900's, vaccinepreventable diseases (VPDs) were the leading cause of death in the United States (US). Before the widespread use of vaccines, 100 out of every 1,000 children born in the US died within the first year of life. Immunizations have not only played an important role in dramatically decreasing infant mortality, immunizations have also prevented disabilities commonly associated with VPDs such as blindness, deafness, and paralysis [2]. Over the lifespan of children born between 1994 and 2014, the Centers for Disease Control and Prevention (CDC) [3] estimate that immunizations will prevent 322 million illnesses, 21 million hospitalizations, and 732,000 deaths. The prevention of VPDs saves the American public an estimated $\$ 1.38$ trillion annually in healthcare costs [3].

A reduction in disease is historically followed by a decreased perception of susceptibility to VPDs, and an increased fear of vaccine side-effects [4]. This shift in perception leads to a decrease in overall vaccination rates and vaccine coverage in communities. Vaccination concerns may remain until VPDs are again seen as an imminent threat [5].

Compulsory vaccination laws were enacted at the beginning of the $20^{\text {th }}$ century [6]. Massachusetts was the first state to implement a mandatory immunization law in 1905, requiring all residents age 21 years and older to receive the smallpox vaccine [7]. However, the Massachusetts' smallpox immunization law met some resistance from residents claiming compulsory vaccination was a violation of their Constitutional rights [8]. The conflict eventually became the seminal court case and well-known legal precedent, Jacobson v. Massachusetts, upholding states authority to require vaccinations for the benefit of public health.

Since the Jacobson v. Massachusetts case, other vaccination laws have been enacted, including those requiring all school-aged children to receive vaccinations prior to school admission [9]. By the early 1980s, all 50 states enacted similar immunization laws [10]. However, states have also retained the ability to allow citizens to legally exempt their children from receiving immunizations while allowing the 
Page 2 of 5

children to attend school [11]. Immunization exemption laws vary by state (Figure 1). There are three common categories of exemptions: religious, personal, and medical [12]. As of 2017, 46 states permit religious exemptions, 17 states allow personal exemptions, and all 50 states grant vaccination exemptions for medical reasons [13]. While these numbers do not coincide with the numbers in the study, it is the most up to date information from the Immunization Action Coalition. Some states also offer temporary medical exemptions.

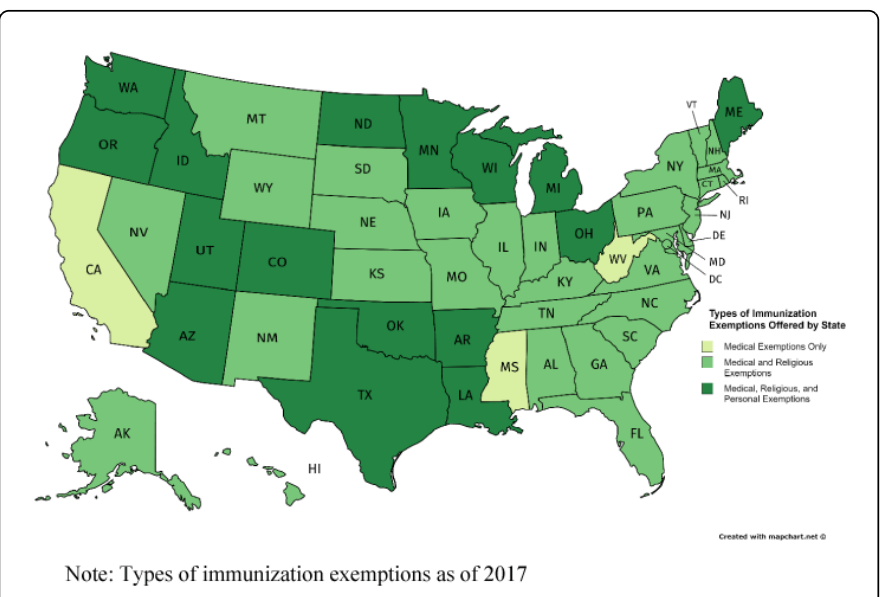

Figure 1: Types of immunization exemptions offered by state.

Common reasons for which parents claim vaccine exemptions include concerns regarding vaccination safety, namely, the belief that vaccines cause a wide variety of conditions such as autism, autoimmune disorders, diabetes, and allergies [14]. Therefore, educating parents on the risks/benefits of vaccines and the dangers of refusing vaccines is a key component of increasing immunization rates and decreasing immunization exemption rates [15-17].

However, not all states require parental vaccination education prior to obtaining an exemption. Available data are, in fact, scarce regarding the process of educating parents on vaccine safety. Therefore, the purpose of this research was to collect data from immunization programs in each of the 50 US states, District of Columbia, US Indian Health Service, and eight US territories regarding: 1) Need for parental signature after reading vaccine risk/benefit statement; 2) Mandatory vaccine education prior to exemption; 3) Cut-off date for mandatory vaccine education; and 4) Regulation of mandatory vaccine education.

\section{Research Questions}

1) Which states require parents to read and sign a vaccine risk/ benefit statement prior to granting an exemption?

2) Which states require mandatory vaccine education prior to obtaining an exemption?

a. Of the states requiring mandatory vaccine education, how close to school admission does the education need to be completed?

b. Of the states requiring mandatory vaccine education, how is mandatory vaccine education regulated?

\section{Methodology}

\section{Participants}

The sample included the immunization program managers of all 50 states, District of Columbia, the US Indian Health Service, and eight US territories (American Samoa, Guam, Marshall Islands, Federal States of Micronesia, Commonwealth of the North Mariana Islands, Puerto Rico, Virgin Islands, and Palau) for a potential sample of 60 entities (collectively, hereafter to be referred to as "states"). The list of managers was generated from state health department websites and cross-checked with the membership of the Association of Immunization Managers (AIM), which is the professional membership organization for immunization program managers. To be eligible for participation, the immunization managers needed to have first-hand knowledge of the immunization exemption procedures for his/her jurisdiction. While all participants were able to answer most of the questions, some of the participants were not able to answer a few of the question but were not eliminated from the study. Managers from all 50 states and 2 US territories (American Samoa and Guam) completed the Qualtrics online questionnaire, resulting in an $86.6 \%$ response rate $(52 / 60)$.

\section{Design}

This study was a descriptive design. The Brigham Young University Institutional Review Board deemed the study exempt because the participants were asked for expert opinions, rather than personal perceptions. Managers were initially contacted by AIM via email to explain the study and eligibility requirements. Following the initial contact, AIM sent an electronic link to all the immunization managers which could be utilized to access a Qualtrics online questionnaire. Three weeks after the distribution of the questionnaire, AIM generated a reminder for all non-responders. All data were collected via the online survey. A $\$ 50$ Visa gift card was offered as an incentive for all eligible managers who completed the study.

\section{Instrument}

The questionnaire was designed by a group of researchers with input from the AIM Research Committee, which includes representatives who are immunization program managers, immunization program staff, and staff from the CDC. The Qualtrics online questionnaire used skip logic, which created unique pathways for each manager to navigate through questions; although each participant responded to the same 18 core questions. Depending on responses to the 18 core questions, some managers were directed to follow-up questions where they could provide additional information. Thus, the number of questions varied for each manager, ranging from 18-27 items.

Data presented in this article are part of a larger study with the results of 2 core and 2 follow-up questions being presented. For the two core questions, participants could select their response from Yes/No/Not Sure/Not Applicable choices. Follow-up questions included one open-ended item and one multiple choice. Remaining data will be reported in a separate article.

\section{Data Analysis}

Quantitative data were entered into SPSS 23 [18]. After the data were entered, two individual researchers checked the data for accuracy. The primary investigator read the responses and the second 
Citation: Eden LM, Dunn EG, Luthy KE, Wells K, Macintosh J, et al. (2017) Identifying United States and Territory Education Requirements for Childhood Vaccination Exemptions. J Vaccines Vaccin 8: 362. doi:10.4172/2157-7560.1000362

Page 3 of 5

investigator reviewed the entered data. Responses were tallied after review.

\section{Results}

\section{Risk/benefit statements}

Participants were asked if parents seeking exemption needed to read a risk/benefit statement and provide a signature, affirming the parents understood the benefits of vaccinations and the risk to their child's health and the health of others by refusing. Of states that responded, 25 of 51 states with a religious exemption (49\%) and 12 of 24 states with a personal exemption $(50.0 \%)$ require a parental signature of risks/benefits of vaccinations statement. Comparatively, 10 of 51 states with a medical exemption (19.6\%), and one of 27 states with a temporary medical exemption $(3.7 \%)$ require a parental signature of risks/benefits of vaccinations statement (Figure 2 and Table 1).

\begin{tabular}{|l|l|l|l|l|}
\hline Responses & $\begin{array}{l}\text { Religious } \\
\mathbf{n = 5 1} \\
\mathbf{n}(\%)\end{array}$ & $\begin{array}{l}\text { Personal } \\
\mathbf{n = 2 4} \\
\mathbf{n}(\%)\end{array}$ & $\begin{array}{l}\text { Medical } \\
\mathbf{n = 5 1} \\
\mathbf{n}(\%)\end{array}$ & $\begin{array}{l}\text { Temporary } \\
\text { Medical } \\
\mathbf{n = 2 7} \\
\mathbf{n}(\%)\end{array}$ \\
\hline Yes & $25(49.0 \%)$ & $12(50.0 \%)$ & $10(19.6 \%)$ & $1(3.7 \%)$ \\
\hline No & $25(49.0 \%)$ & $10(42.0 \%)$ & $39(76.5 \%)$ & $25(92.6 \%)$ \\
\hline Not sure & $1(2.0 \%)$ & $2(8.0 \%)$ & $2(3.9 \%)$ & $1(3.7 \%)$ \\
\hline
\end{tabular}

Table 1: Risk/benefit Vaccination Statements on Exemption Forms.

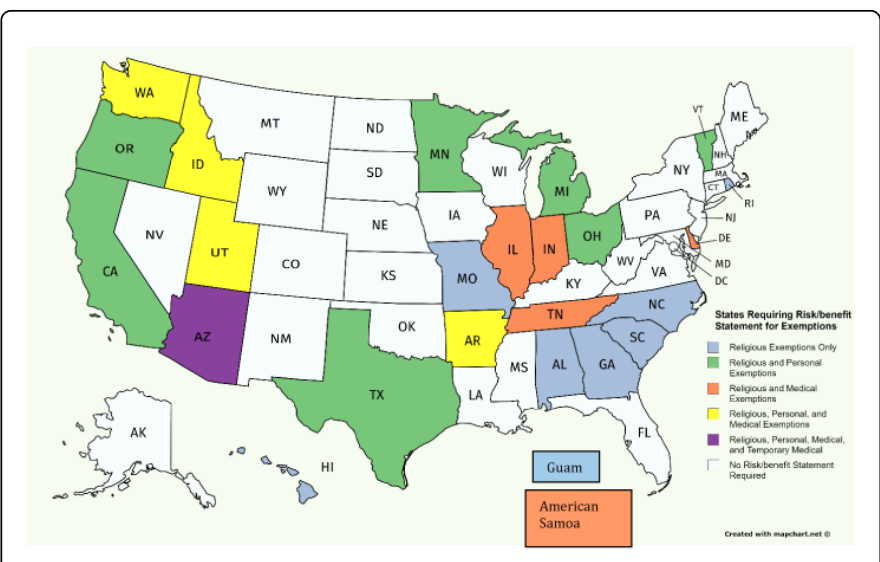

Figure 2: States requiring risk/benefit statement for each type of exemption form.

\section{Parental vaccine education requirements}

States were asked whether or not mandatory parental education was required prior to obtaining an exemption. Only 13 of 52 (25\%) states who responded reported a parental vaccine education requirement. Of the states reporting a mandatory parental education requirement, 9 of $13(69.2 \%)$ confirmed parents needed to complete vaccine education prior to obtaining religious exemptions, 7 of 13 $(53.8 \%)$ reported a parental education requirement for personal exemptions, and 4 of 13 (30.8\%) required parental education for medical exemptions. No states reported mandatory vaccine education for parents seeking a temporary medical exemption (Table 2).

\begin{tabular}{|c|c|c|c|c|}
\hline State & $\begin{array}{l}\text { Religious } \\
\text { Exemption } \\
\text { Form }\end{array}$ & $\begin{array}{l}\text { Personal } \\
\text { Exemption } \\
\text { Form }\end{array}$ & $\begin{array}{l}\text { Medical } \\
\text { Exemption } \\
\text { Form }\end{array}$ & $\begin{array}{l}\text { Temporary } \\
\text { Medical } \\
\text { Exemption } \\
\text { Form }\end{array}$ \\
\hline Alabama & $Y$ & -- & $\S$ & $\S$ \\
\hline $\begin{array}{l}\text { American } \\
\text { Samoa }\end{array}$ & $Y$ & -- & $\mathrm{Y}$ & -- \\
\hline Arkansas & $Y$ & $Y$ & $Y$ & -- \\
\hline California & $\mathrm{N}$ & $Y$ & $\mathrm{~N}$ & $\mathrm{~N}$ \\
\hline Delaware & + & -- & + & -- \\
\hline Florida & $Y$ & -- & $\mathrm{N}$ & $\mathrm{N}$ \\
\hline Michigan & $Y$ & $Y$ & $\mathrm{~N}$ & -- \\
\hline Oregon & $Y$ & $Y$ & $\mathrm{~N}$ & $\mathrm{~N}$ \\
\hline $\begin{array}{l}\text { South } \\
\text { Carolina }\end{array}$ & $\S$ & -- & П & -- \\
\hline Texas & $\S$ & $\S$ & $\mathrm{N}$ & -- \\
\hline Utah & $Y$ & $Y$ & Y & -- \\
\hline Vermont & $Y$ & $Y$ & $\mathrm{~N}$ & $\mathrm{~N}$ \\
\hline Washington & $Y$ & $Y$ & Y & -- \\
\hline \multicolumn{5}{|c|}{$\begin{array}{l}Y=\text { Yes } \\
N=\text { No } \\
\text { § Required to offer education but parents can refuse } \\
+ \text { No data } \\
\text { I Not sure } \\
\text { "- Type of exemption not offered } \\
\text { "Seither et al., } 2015 \\
\text { Note: Data collected prior to } 2016 \text { changes in California vaccination exemption } \\
\text { laws. }\end{array}$} \\
\hline
\end{tabular}

Table 2: States requiring mandatory education prior to exemption and kindergarten exemptions for 2014-15 school year.

The 13 states reporting a mandatory education requirement were also asked to indicate whether the parental education needed to be received within a certain time frame prior to school admission. Four states responded: two states (American Samoa and Oregon) reported that the mandatory education could be received "any time" a parent sought an exemption, and one state (California) required parental vaccine education within 6 months of admission. Another state (Utah) reported that the acceptable parental vaccine education time frame differed with each local health department.

The 13 states with a mandatory vaccine education requirement were also asked how the parent vaccine education was regulated for each type of exemption. Of those with a mandatory vaccine education requirement, 10 states specified how religious exemptions were regulated, 7 states reported on regulation of personal exemptions, 5 states declared how medical exemptions were regulated and 1 state reported on the regulation of temporary medical exemptions (Table 3). For states that mandated parental vaccine education prior to exemption, most commonly the education was regulated by law (Table $3)$. 


\begin{tabular}{|l|l|l|l|}
\hline \multirow{2}{*}{ State } & \multicolumn{2}{|l|}{ Regulation Type } & \multicolumn{2}{l|}{} \\
\cline { 2 - 4 } & Statute & Administrative Rule & School Policy \\
\hline Alabama & & & R \\
\hline American Samoa & R, M & & \\
\hline Arkansas & R, P & M \\
\hline California & P & & \\
\hline Delaware+ & & & R \\
\hline Florida & & R, P & \\
\hline Michigan & M & & \\
\hline Oregon & R, P, M, TM & & \\
\hline South Carolina & & R, P & \\
\hline Texas & & & \\
\hline Utah+ & & & \\
\hline Vermont & R, P & R, P, M & \\
\hline Washington & & & \\
\hline $\begin{array}{l}\text { R=Religious exemption } \\
\text { P=Personal exemption } \\
\text { M=Medical exemption } \\
\text { TM=Temporary medical exemption } \\
+=\text { No data }\end{array}$ & & \\
\hline
\end{tabular}

Table 3: Regulation of mandatory vaccine education.

\section{Discussion}

In the US, childhood vaccine requirements are established and regulated at the state level for public and private schools, pre-schools, and day-care [19]. Despite existing laws, the number of religious and personal vaccine exemption rates continue to rise in the US $[16,20]$. It is, therefore, prudent for states to actively promote public policy that effectively decreases vaccine exemption rates [21].

In response to the steady increase in vaccination exemption rates, the Department of Health and Human Services issued a statement in which they strongly recommended "...that parents, providers, and the general public should be fully informed about the benefits and risks of vaccination" (para. 42) [22]. Recognizing that having an in-depth vaccine conversation with parents can be time intensive, some public health organizations have instead opted to offer a vaccine risks/benefits statement for the parents to read and sign. In this study, almost half of the states required parents to read and sign a vaccine risks/benefits statement for religious and personal exemptions. Thirteen states reported mandatory vaccine education for exempting parents; the regulation of mandated vaccine education and delivery of the education varied from state-to-state. For example, Arizona parents must either acknowledge potential risks associated with vaccine exemptions via waiver forms, or receive written materials prior to claiming an exemption. California, Oregon, and Washington take a more interactive approach by requiring exempting parents to either engage in a conversation with a health care provider or complete online modules discussing the benefits and risks of vaccinations [23].

The intention is that education requirements will impact exemption rates. When considering our study, states with the lowest 2015-2016 kindergarten exemption rates of $0.1-1.1 \%$ (Mississippi, West Virginia, Alabama, Louisiana, Kentucky, New York, District of Columbia, North Carolina, Rhode Island and Tennessee) [24] only Alabama required parents to receive education prior to claiming an exemption. In contrast, of the states with the highest percentage of 2015-2016 kindergarten exemptions, ranging from 4.0\%-6.3\% (Oregon, Idaho, Alaska, Vermont, Arizona, Maine, Washington and Colorado) [24], four states (Oregon, Vermont, Utah and Washington) required mandatory vaccine education prior to approval of an exemption.

However, without further analysis, it is unclear how an education requirement impacts exemption rates. One study [25], found that kindergarten exemption rates declined from $7.1 \%$ to $6 \%$ in one year that since enacting a mandatory vaccine education law in Oregon in 2013-14. In addition, the state of Washington reported a decrease in exemptions from $7.5 \%$ to $4.5 \%$ after exemption laws were strengthened to include a separate certificate of exemptions in 2008-2009 and health care provider signature in 2011-2012 [26]. Therefore, there is limited evidence into the impact of education on exemption rates.

In theory, education can be an effective tool to help parents understand the benefits of vaccinations and the risks associated with refusing vaccinations $[27,28]$. The overall goal in requiring vaccine education prior to exemption is that educated parents will choose to vaccinate their children because they more fully understand the risks and benefits of vaccinations [23]. Nevertheless, additional research is needed to determine the impact of education requirements on exemption rates and which mandatory educational approach is the most effective in reducing exemption rates.

\section{Limitations}

There are limitations to this study. This was the first time the questionnaire was used in a study. Responses to the question regarding the risk/benefit statement were inconsistent with responses to what type of exemptions the participant's states allow, indicating confusion with the tool. Additionally, state immunization exemption laws change from year to year. Because this data was collected in 2015, the total number of religious, personal, medical and temporary medical exemptions differs from the 2017 data provided by the Immunization Action Coalition [13]. This study did not examine or compare state exemption rates with the time education requirements were implemented. Therefore, we were unable to evaluate the effect education has on exemption rates.

\section{Recommendations for Future Research}

While states were asked about the presence of mandatory vaccination education for parents seeking an immunization exemption, it would be helpful to know what specific information is included in the state's mandatory vaccination education. Future research can also identify how the states are evaluating the effectiveness of the mandatory vaccination education and whether or not exemption rates have declined since instituting a vaccination education requirement.

\section{Conclusion}

Immunizations are the most effective method of preventing VPDs. Nevertheless, all states have enacted medical, temporary medical, 
Citation: Eden LM, Dunn EG, Luthy KE, Wells K, Macintosh J, et al. (2017) Identifying United States and Territory Education Requirements for Childhood Vaccination Exemptions. J Vaccines Vaccin 8: 362. doi:10.4172/2157-7560.1000362

Page 5 of 5

personal, and/or religious vaccine exemptions, allowing unvaccinated children to enroll and attend public or private school. Thirteen states responding to this survey, reported having state education-related requirements for parents seeking to obtain a vaccination exemption for their school-aged children; however, more research is needed to fully understand the effectiveness of the education requirement on exemption rates. Familiarity with various state vaccine education requirements may aid policymakers who are considering enacting mandatory vaccine education in his or her state.

\section{Acknowledgements}

We would like to acknowledge the Association of Immunization Managers (AIM) research committee for their writing assistance and proof reading of the article. Additionally, we appreciate their input and feedback on the questionnaire for this study.

The authors did not receive funding or benefits from commercial sources. There are no other financial interests for all authors that could create a potential conflict of interest or the appearance of a conflict of interest with regard to the work.

\section{Financial Support}

The Brigham Young University Office of Research and Creative Activities provided funding for this research. This funding source was not involved in the conduction of the research or preparation of the article.

\section{References}

1. Kraemer JD, Gostin LO (2011) Vaccine liability in the Supreme Court: Forging a social compact. The Journal of the American Medical Association 305: 1900-1901.

2. Anderson VL (2015) Promoting childhood immunizations. J Nurse Pract 11:1-10.

3. https://www.cdc.gov/mmwr/preview/mmwrhtml/mm6316a4.html

4. Dube E, Laberge C, Guay M, Bramadat P, Roy R, et al. (2013) Vaccine hesitancy. Human Vaccines Immunother 9: 1763-1773.

5. Atwell JE, Salmon DA (2014) Pertussis resurgence and vaccine uptake: Implications for reducing vaccine hesitancy. Pediatrics 3: 602-604.

6. Hodge JG, Gostin LO (2002) School vaccination requirements: Historical, social, and legal perspectives. KY Law J 4: 831-890.

7. Stewart AM, Rosenbaum S (2010) Vaccinating the health-care workforce State law vs. institutional requirements. Public Health Rep 4: 615-618.

8. Marshall LW, Marshall BL, Valladares G (2010) Federal and state public health authority and mandatory vaccination: Is Jacobson v Massachusetts still valid? Am J Disaster Med 2: 107-112.
9. http://www.cdc.gov/vaccines/imz-managers/laws/state-reqs.html.

10. Malone KM, Hinman AR, Goodman, Hoffman, Lopez, et al. (2007) The public health imperative and individual rights. Law in Public Health Practice. New York: Oxford University Press, USA.

11. Diekema DS (2014) Personal belief exemptions from school vaccination requirements. Annual Review of Public Health 35: 275-292.

12. https://www.cdc.gov/vaccines/imz-managers/coverage/schoolvaxview/ requirements/exemption.html.

13. http://www.immunize.org/laws/exemptions.asp

14. Salmon DA, Dudley MZ, Glanz JM, Omer SB (2015) Vaccine Hesitancy: Causes, Consequences, and a Call to Action. Am J Prev Med 49: S391-398

15. Horne Z, Powell D, Hummel JE, Holyoak KJ (2015) Countering antivaccination attitudes. Proceedings of the National Academy of Sciences 33: 10321-10324.

16. Bradford WD, Mandich A (2015) Some state vaccination laws contribute to greater exemption rates and disease outbreaks in the United States. Health Affairs 8: 1383-1390.

17. Joshi A, Lichenstein R, King J, Arora M, Khan S (2009) Evaluation of a computer-based patient education and motivation tool on knowledge, attitudes and practice toward influenza vaccination. Int Electr J Health Edu 12: 1-15.

18. IBM SPSS Statistics for Windows. Version 23.0. Armonk, NY: IBM Corp; 2015.

19. Centers for Disease Control and Prevention (2015) Centers for Disease Control and Prevention.

20. Omer SB, Richards JL, Ward M, Bednarczyk RA (2012) Vaccination policies and rates of exemption from immunization, 2005-2011. New Eng J Med 12: 1170-1171.

21. Wang E, Clymer J, Davis-Hayes C, Buttenheim A (2014) Nonmedical exemptions from school immunization requirements: A systematic review. Am J Public Health 11: e62-e84.

22. https://www.hhs.gov/nvpo/nvac/reports-and-recommendations/thestandards-for-pediatric-immunization-practice/index.html.

23. Yang YT, Silverman RD (2015) Legislative prescriptions for controlling nonmedical vaccine exemptions. J Am Med Asso 3: 247-248.

24. https://www.cdc.gov/vaccines/imz-managers/coverage/schoolvaxview/ data-reports/exemptions-reports/2015-16.html

25. Seither R, Calhoun K, Knighton CL, Mellerson J, Meador S, et al. (2015) Vaccination coverage among children in kindergarten-United States, 2014-15 school year. Morbidity and MMWR Surveill Summ 33: 897-904.

26. http://www.doh.wa.gov/Portals/1/Documents/Pubs/348-548-SY2015-16ImmunizationGraphs.pdf.

27. Luthy KE, Sperhac AM, Faux SA, Miner JK (2010) Improving immunization rates in the clinic and in the community. Contemp Pediatr 9: 54-60.

28. Poland CM, Poland GA (2011) Vaccine education spectrum disorder: The importance of incorporating psychological and cognitive models into vaccine education. Vaccine 37: 6145-6148. 